\title{
Hibrid Çok Kriterli Karar Verme Yöntemi Temelinde İş Güvenliği Uzmanı Seçimi
}

\author{
Ömer Faruk EFE*
}

Afyon Kocatepe Üniversitesi, Dinar Uygulamalı Bilimler Yüksekokulu, İş Sağlığı ve Güvenliği Bölümü, 03200, Afyonkarahisar

Geliş / Received: 09/10/2018, Kabul / Accepted: 30/08/2019

$\ddot{\mathbf{O} z}$

Rekabetin her geçen gün arttığı günümüzde, organizasyonların başarılı olabilmesi için en uygun personelin seçilmesi insan kaynakları yönetiminin etkinliği açısından oldukça önemlidir. İnsan kaynakları yönetiminin etkinliği arttıkça, organizasyonların başarısı da o oranda artacaktır. İşletmelerin iş güvenliği uzmanlarına olan ihtiyacı ise her geçen gün artmaktadır. $\mathrm{Bu}$ çalışma iş güvenliği uzmanı seçimi için hibrid bir model sunmaktadır. Bulanık mantık dilsel değişkenleri kullanarak belirsiz ortamda karar vermede önemli bir katkı sağlamaktadır. Bulanık AHP (Analitik Hiyerarşi Prosesi) ve Bulanık TOPSIS (İdeal Çözüm için Benzerlik Sıralama Tercihi için Teknik) yaklaşımlarını kullanan hibrid model personel seçiminde kullanılmıştır. Bulanık AHP ile personel seçiminde incelenen kriterlerin önem dereceleri belirlenmiştir. Bulanık TOPSIS ile kriterler temelinde beş aday personel değerlendirilmiştir. Bunlar arasında en uygun personel adayının aday 1 olduğu görülmüştür. Önerilen modelin etkinliğini göstermek için sayısal bir örnek sunulmuştur. Elde edilen sonuçlar, iş güvenliği uzmanı personeli için aranan en önemli kriterin "bilgisayar yeteneği”" ile "bireysel özellikler ve dış görünüm”, en az öneme sahip kriterin ise "eğitim düzeyi” olduğunu göstermiştir.

Anahtar Kelimeler: Bulanık AHP, Bulanık TOPSIS, Personel Seçimi, İş Güvenliği Uzmanı.

\section{Selection of Occupational Safety Specialist Based on Hybrid Multi Criteria Decision Making Method}

\begin{abstract}
Nowadays, when the competition is increasing day by day, the selection of the most suitable personnel for the success of the organizations is very important for the effectiveness of human resources management. As the efficiency of human resources management increases, the success of organizations will increase. Businesses' need for occupational safety specialist is increasing day by day. This paper provides a hybrid model to select the occupational safety specialist selection process. Fuzzy logic makes a significant contribution to decision making using linguistic variables in uncertain environment. Fuzzy AHP (Analytic Hierarchy Process) and Fuzzy TOPSIS (Technical Solution for Similarity Sequence Preference for Ideal Solution) hybrid model were used in personnel selection. The importance of the criteria examined in the selection of personnel with fuzzy AHP was determined. Five candidates were evaluated on the basis of criteria with fuzzy TOPSIS. It is seen that the most suitable personnel candidate is candidate 1 . A numerical example is presented to illustrate the effectiveness of the proposed model. The results showed that the most important criterion for safety specialist personnel is "individual characteristics and external appearance with computer ability, otherwise education level is the least important criterion.
\end{abstract}

Keywords: Fuzzy AHP, Fuzzy TOPSIS, Personnel Selection, Occupational Safety Specialist 


\section{Giriş}

İnsan kaynakları yönetimi sürecinde, personel seçimi önemini her daim korumaktadır. En uygun profile sahip kişinin en uygun işe yerleştirilmesini sağlayan personel seçimi, tüm işletmeler için önemli bir konudur. Aday araştırma ve bulma çabaları sonucu bir aday havuzu oluşturulduktan sonra, sıra işe alınacak uygun kişilerin seçimine gelir. Personel istihdamının bu son aşaması, "personel seçimi" veya "işe alma" olarak adlandırılır (Kaynak, 1998; Sabuncuoğlu, 2002).

Günümüzde işletmelerin verimliliği üzerine etki eden birçok faktör olmasına rağmen en önemlisi insan faktörüdür. İşletmelerde, en alt kademeden en üst kademeye kadar birbirinden farklı niteliğe ve kişiliğe sahip çalışanlara ihtiyaç duyulmaktadır. İşletmelerde insan kaynakları dinamik bir yapıda olup, işten ayrılma, emeklilik, istifa, iş değiştirme, ek iş gücü ihtiyacı vb. nedenlerle değişkenlik arz etmektedir. İnsan kaynakları fonksiyonunun dinamik yapısı işletmelerde işe uygun nitelik ve kişilikte personel istihdam edilmesinin, işletmenin amaçlarına ulaşmasında önemli bir süreç olmasına neden olmuştur. Literatürde, personel seçimi için kullanılan ilk teknikler; yazılı sinav, test ve sözlü sinavdır (Arvey, 1982). Personel seçiminde yaygın olarak kullanılan yöntem ilanlardır. İlanlar gazete, dergi, anlaşmalı iş arama siteleri yoluyla gerçekleştirilir.

Personel adaylarının farklı teknikler ile değerlendirilmesi, işletmenin ihtiyaç duyduğu personelin temini için gerekli olmasına karşın yeterli değildir. Ölçme ve değerlendirmeye temel olacak kriterlerin net olarak belirlenmesi ve belirlenmiş bu kriterlerin ağırlıklarının da belirlenmesi gerekir. Çünkü her bir kriterin o iş için personel ölçme ve değerlendirilmesinde farklı önemi ya da ağırlığı bulunmaktadır. Örneğin; iş tecrübesi kriteri, herhangi bir sektör veya işletme için çok önemli kabul edilirken, başka bir sektör veya işletme için daha az öneme sahip olabilmektedir. $\mathrm{Bu}$ nedenle, belirli kriter ve ağırlıkları ele almayan bu yöntemler objektiflikten uzak ölçme ve değerlendirme sürecine ve buna bağlı olarak yanlış kararların alınmasına neden olmaktadir. $\mathrm{Bu}$ kararlar genellikle karmaşık ve belirsiz bir ortamda verilir. Birbirleriyle çelişen birçok niceliksel ve niteliksel kriter aynı anda dikkate alınmalıdır. Bulanık çok kriterli karar verme yöntemleri bu sorunlara çözüm olmak amaciyla geliştirilmiştir.

$\mathrm{Bu}$ çalışmanın geri kalanı aşağıdaki gibidir. Literatür araştırması yapılarak personel seçimiyle ilgili yapılmış çalışmalar sunulmuştur. Bulanık Mantık, AHP ve TOPSIS teknikleri kısaca anlatılmıştır. Daha sonra uygulamadan elde edilen sonuçlar anlatılmıştır.

Daha objektif bir personel seçiminin yapılabilmesi için yeni yöntemler, farklı çalışmalar yapılmaktadır. Literatürde yer alan bazı çalışmalar, Tablo 1'de kısaca gösterilmiştir.

Tablo 1. Personel seçiminde ÇÖKV tekniklerini kullanan çalışmalar

\begin{tabular}{lll}
\hline Yazar(lar) & $\begin{array}{l}\text { Seçim } \\
\text { Konusu }\end{array}$ & $\begin{array}{l}\text { Kullanılan } \\
\text { Yöntemler }\end{array}$ \\
\hline $\begin{array}{l}\text { Özgörmüş } \\
\text { (2005) }\end{array}$ & vd. Tedarik & Bulanık AHP \\
& $\begin{array}{l}\text { Planlama } \\
\text { Mühendisi }\end{array}$ \\
& Seçimi \\
\hline Dağdeviren & Üst Düzey & Bulanık AHP \\
(2007) & Yönetici & \\
\hline Chen vd. (2009) & Yurtdışı & PROMETHEE \\
& Pazarlama & \\
& Müdürü & \\
\hline Dereli vd. (2010) & Endüstri & Bulanık \\
& Mühendisi & PROMETHEE \\
\hline Kelemenis & ve Bilişim & Bulanık \\
Askouris (2010) & Uzmanı & TOPSIS \\
\hline
\end{tabular}




\begin{tabular}{|c|c|}
\hline $\begin{array}{lrl}\text { Dursun ve } & \text { Endüstri } \\
\text { Karsak (2010) } & \text { Mühendisi }\end{array}$ & $\begin{array}{l}\text { Çok Kriterli } \\
\text { Bulanık } \\
\text { Mantık, } \\
\text { TOPSIS }\end{array}$ \\
\hline $\begin{array}{l}\text { Aksakal } \\
\text { Dağdeviren } \\
(2010) \\
\end{array}$ & $\begin{array}{l}\text { ANP ve } \\
\text { DEMATEL }\end{array}$ \\
\hline $\begin{array}{ll}\text { Zolfani vd. (2012) } & \text { Kalite } \\
& \text { Kontrol } \\
& \text { Yöneticisi } \\
\end{array}$ & $\begin{array}{l}\text { AHP- } \\
\text { COPRAS G }\end{array}$ \\
\hline Kabak (2013) & $\begin{array}{l}\text { Bulanik } \\
\text { DEMATEL- } \\
\text { ANP }\end{array}$ \\
\hline $\begin{array}{l}\text { vd. Proje } \\
\text { Yöneticisi }\end{array}$ & $\begin{array}{l}\text { Çok Kriterli } \\
\text { Bulanık } \\
\text { Mantık }\end{array}$ \\
\hline $\begin{array}{llc}\text { Bedir } & \text { ve } & \text { Eren Satış } \\
(2015) & & \text { Danışmanı } \\
\end{array}$ & $\begin{array}{l}\text { AHP- } \\
\text { PROMETHEE }\end{array}$ \\
\hline $\begin{array}{ll}\text { Akça vd. (2018) } & \text { Finans } \\
& \text { Yöneticisi }\end{array}$ & ANP \\
\hline $\begin{array}{lcc}\text { Efe } & \text { ve } & \text { Kurt Personel } \\
(2018) & \text { seçimi }\end{array}$ & $\begin{array}{l}\text { Bulanik } \\
\text { Mant1k, } \\
\text { TOPSIS }\end{array}$ \\
\hline $\begin{array}{ll}\text { Efe ve Efe (2018) } & \begin{array}{l}\text { Personel } \\
\text { seçimi }\end{array}\end{array}$ & $\begin{array}{l}\text { Sezgisel } \\
\text { bulanık küme, } \\
\text { AHP-VIKOR }\end{array}$ \\
\hline
\end{tabular}

Literatürde yer alan bir diğer personel seçim yöntemi çok kriterli analizlerdir (Bohanec vd, 1992; Timmermans ve Vlec 1992; Gardiner ve Armstrong-Wright 2000; Chen ve Wang, 2009). Özellikle, büyük karmaşık problemlerde birden fazla faktörün değerlendirilmesinde çok kriterli analiz yöntemleri kullanılmıştır. $\mathrm{Bu}$ çalışmada literatürde yer alan bulanık mantık ve çok kriterli analiz çalışmalarını birleştiren bir algoritma önerilmiş ve önerilen algoritmada Bulanık Analitik Hiyerarşi Prosesi ile Bulanık TOPSIS yöntemi kullanılmıştır. Önerilen algoritma bir OSGB'ye (Ortak sağlık güvenlik birimi) boş bir pozisyon için asgari şartları yeterli olan beş iş güvenliği uzmanı adayının değerlendirilmesi ve belirlenmesi amacıyla uygulanmıştır. İş güvenliği uzmanlarına olan ihtiyaç her geçen gün daha fazla önem kazanmaktadır. Disiplinlerarası bir alan olan iş güvenliğinde, bu hizmeti verecek olan en uygun iş güvenliği uzmanının seçimi işletme açısından oldukça önemlidir. Yapılan literatür taramaları sonucunda bulanık AHP ve bulanık TOPSIS yaklaşımlarını kullanarak yapılan, iş güvenliği uzmanı personel seçimine rastlanılmamıştır. $\mathrm{Bu}$ nedenle bu çalışma özgün bir çalışma niteliği taşımaktadır. Uzmanlar karar verme sırasında kesin değerleri kullanırken bazı değerlendirmeleri net olarak ifade edemezler. Fakat bulanık mantık dilsel değişkenleri kullanarak belirsiz ortamda karar vermede önemli bir katkı sağlamaktadır. Kriterlerin önem derecelerinin belirlenmesi ve kriterler temelinde adayların değerlendirilmesinde bulanık mantık kullanılmış böylece uzmanlar görüşlerini dilsel değişken olarak ifade edebilmiştir. Yapılan uygulamada Bulanık AHP ile personel seçiminde incelenen kriterlerin önem dereceleri belirlenmiştir. Bulanık TOPSIS ile kriterler temelinde aday personeller değerlendirilmiştir.

\section{Materyal ve Metot}

Personel seçimi için Bulanık Genişletilmiş AHP ve Bulanık TOPSIS bütünleşik yöntemi uygulanmıştır. Personel seçiminde kriter ağırlıklarının belirlenmesi için Chang (1996) çalışmasında önerilen Bulanık Genişletilmiş AHP uygulanmıştır. İş güvenliği uzmanına ait bir pozisyona personel alımı için "bireysel Özellikler ve diş görünüm $\left(\mathrm{K}_{1}\right)$ ", "bilgisayar yeteneği $\left(\mathrm{K}_{2}\right)$ ", "tecrübe/iş deneyimi $\left(\mathrm{K}_{3}\right)$ ", "yabanc1 dil bilgisi $\left(\mathrm{K}_{4}\right)$ " ve "eğitim düzeyi $\left(\mathrm{K}_{5}\right)$ " değerlendirme kriterleri olarak uzman görüşleri ve literatürden faydalanılarak belirlenmiştir. $\mathrm{K}_{3}$, ve $\mathrm{K}_{4}$ kriterleri Dursun ve Kasnak (2010) ve Zhang ve Liu (2011) çalışmalarından; $\mathrm{K}_{1}, \mathrm{~K}_{2}$ ve $\mathrm{K}_{5}$ kriterleri ise uzman görüşleri yardımıyla belirlenmiştir. İş güvenliği uzmanı olmak için boş pozisyona başvuran adaylardan ön elemeyi geçen 5 aday alternatif olarak belirlenmiştir. Uzmanlar ikili karşılaştırma matrislerini 
oluştururken Tablo 2'de gösterilen dilsel değişkenlerden faydalanmıştır.

Her bir uzmanın ikili karşılaştırma matrisi tek bir ikili karşılaştırma matrisine aşağıdaki gibi dönüştürülür: Örneğin "tecrübe/iş deneyimi" kriteri "yabanc1 dil" kriterine göre üç karar verici tarafından sırasıyla şöyle ifade edilmiştir: (KDG), (ÇG), (MG) yani sayısal karşılıkları $\quad(3 / 2,2,5 / 2), \quad(5 / 2,3,7 / 2)$, $(7 / 2,4,9 / 2)$. Üç karar vericiye göre alt sınırın minimum, üst sınırın maksimum ve orta değerin ortalamaları alınarak tek bir bulanık say1 elde edilir. Min $(3 / 2,5 / 2,7 / 2)=3 / 2$. $\operatorname{Maks}(5 / 2,7 / 2,9 / 2)=9 / 2 . \quad(2+3+4) / 3=3$. Sonuç olarak üç karar vericinin ortak görüşü şöyle ifade edilir: $(3 / 2,3,9 / 2)$.

Tablo 2. Kriterler için dilsel ifadeler ve sayısal karşılıkları.

\begin{tabular}{ll}
\hline Tanım & Sayısal Oran \\
\hline Mutlak Güçlü (MG) & $(7 / 2,4,9 / 2)$ \\
\hline $\begin{array}{l}\text { Çok Güçlü (ÇG) } \\
\text { Kuvvetli Derecede Güçlü } \\
\text { (KDG) }\end{array}$ & $(5 / 2,3,7 / 2)$ \\
\hline Biraz Güçlü (BG) & $(2 / 3,1,3 / 2)$ \\
\hline Eşit (E) & $(1,1,1)$ \\
\hline 1/BG & $(2 / 3,1,3 / 2)$ \\
\hline 1/KDG & $(2 / 5,1 / 2,2 / 3)$ \\
\hline 1/ÇG & $(2 / 7,1 / 3,2 / 5)$ \\
\hline 1/MG & $(2 / 9,1 / 4,2 / 7)$ \\
\hline
\end{tabular}

Bulanık genişletilmiş AHP kısaca aşağıdaki gibidir (Chang, 1996; Lee, 2009; Shaw vd., 2012):

İki üçgensel bulanık sayı $M_{1}\left(m_{1}^{-}, m_{1}, m_{1}^{+}\right)$ve $M_{2}\left(m_{2}^{-}, m_{2}, m_{2}^{+}\right)$Şekil 1'de gösterilmiştir (Lee, 2009). $\quad m_{1}^{-} \geq m_{2}^{-}, m_{1} \geq m_{2}, m_{1}^{+} \geq m_{2}^{+}$iken olabilirlik derecesi 1 olarak belirlenir.

$V\left(M_{1} \geq M_{2}\right)=1$

En yüksek kesişim noktasının ordinatı aşağıdaki gibidir:
$V\left(M_{2} \geq M_{1}\right)=\operatorname{hgt}\left(M_{1} \cap M_{2}\right)=\mu(d)=$

$\frac{m_{1}^{-}-m_{2}^{+}}{\left(m_{2}-m_{2}^{+}\right)-\left(m_{1}-m_{1}^{-}\right)}$

Bulanık sentetik derece değeri aşağıdaki gibidir:

$F i=\sum_{j=1}^{m} M_{g i}^{j} \times\left[\sum_{i=1}^{n} \sum_{j=1}^{m} M_{g i}^{j}\right]^{-1} i=1,2, \ldots, n$

$\sum_{j=1}^{m} M_{g i}^{j}=\left(\sum_{j=1}^{m} m_{i j}^{-}, \sum_{j=1}^{m} m_{i j}, \sum_{j=1}^{m} m_{i j}^{+}\right)$,

$j=1,2, \ldots, m$

$\left[\sum_{i=1}^{n} \sum_{j=1}^{m} M_{g i}^{j}\right]^{-1}$

$=\left(\frac{1}{\sum_{i=1}^{n} \sum_{j=1}^{m} M_{i j}^{+}}, \frac{1}{\sum_{i=1}^{n} \sum_{J=1}^{m} M_{i j}}, \frac{1}{\sum_{i=1}^{n} \sum_{j=1}^{m} M_{i j}^{-}}\right)$

$V\left(F \geq F_{1}, F_{2}, \ldots, F_{k}\right)=\min V\left(F \geq F_{i}\right)$,

$i=1,2, \ldots, k$

$d\left(F_{i}\right)=\min V=W_{i}^{\prime}$

$k=1,2, \ldots, n$ ve $k \neq i$

Kriter ağırlıkları aşağıdaki gibi belirlenir:

$W^{\prime}=\left(W_{1}^{\prime}, W_{2}^{\prime}, \ldots, W_{n}^{\prime}\right)^{T}$

Kriterlerin normalize edilmiş hali aşağıdaki gibidir:

$W=\left(W_{1}, W_{2}, \ldots, W_{n}\right)^{T}$

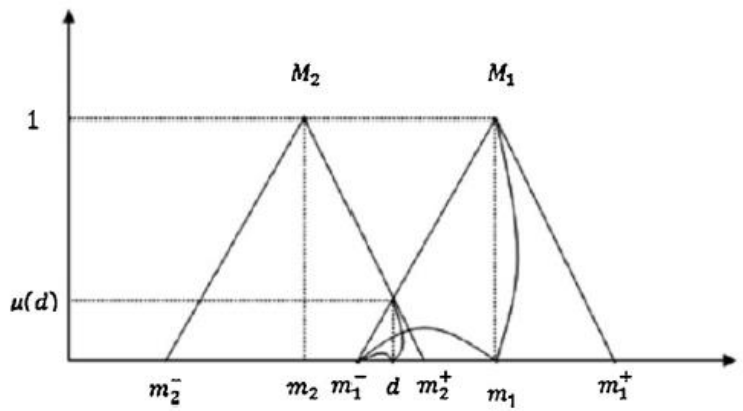

Şekil 1. İki üçgensel bulanık sayı

Hwang ve Yoon (1981) tarafindan önerilen TOPSIS metodu alternatifleri siralarken 
negatif ve pozitif ideal çözümleri inceler. $\mathrm{Bu}$ çalışmada personel adaylarını değerlendirirken bulanık TOPSIS yönteminden yararlanılmıştır. Belirsiz ortamda karar vermek için bulanık mantık yaklaşımı önerilmiştir. Son yıllarda bulanık TOPSIS yöntemi, tedarikçi, tesis yeri, makine ekipman, yazılım ve insan kaynakları seçimi gibi farklı alanlarda uygulanmıştır (Efe, 2016; Efe vd., 2015; Yerlikaya, 2017; Ervural vd., 2016; Erden vd., 2019). Bulanık TOPSIS yönteminde sonuç elde edilirken pozitif ve negatif ideal çözümden uzaklıklar hesaplanmaktadır. Bulanık TOPSIS yöntemi uygulanırken Junior vd. (2014) ve Efe (2016) makaleleri kullanılmıştır.

Kriterler temelinde alternatifleri değerlendirirken karar vericiler Tablo 3'te gösterilen dilsel değişkenleri kullanmışlardır. Yine karar vericilerin görüşleri tek bir görüşe dönüştürülerek yukarıda ifade edilen yöntemden yararlanılmıştır.

Tablo 3. Alternatiflerin sıralaması için dilsel ifadeler

\begin{tabular}{ll}
\hline \multicolumn{1}{c}{ Tanım } & Sayısal oran \\
\hline Çok zayıf $(C ̧ Y)$ & $(1,1,3)$ \\
\hline Zayıf $(\mathrm{Z})$ & $(1,3,5)$ \\
\hline Orta $(\mathrm{O})$ & $(3,5,7)$ \\
\hline İyi $(\mathrm{I})$ & $(5,7,9)$ \\
\hline Çok İyi $($ Çİ) & $(7,9,11)$ \\
\hline
\end{tabular}

$\tilde{A}_{i j}$ karar vericiler tarafindan oluşturulmuş başlangıç matrisidir.

$\tilde{A}_{i j}=\left[\begin{array}{cccc}\tilde{a}_{11} & \tilde{a}_{12} & \ldots & \tilde{a}_{1 n} \\ \tilde{a}_{21} & \tilde{a}_{22} & \ldots & \tilde{a}_{2 n} \\ \vdots & \vdots & \vdots & \vdots \\ \tilde{a}_{m 1} & \tilde{a}_{m 2} & \ldots & \tilde{a}_{m n}\end{array}\right]$

A matrisinden normalize edilmiş bulanık karar matrisi $(\tilde{R})$ elde edilir:

$$
\tilde{r}_{i j}=\frac{\tilde{a}_{i j}}{\sqrt{\sum_{k=1}^{m} a_{k j}^{2}}}
$$

$\tilde{R}_{i j}=\left[\begin{array}{cccc}\tilde{r}_{11} & \tilde{r}_{12} & \ldots & \tilde{r}_{1 n} \\ \tilde{r}_{21} & \tilde{r}_{22} & \ldots & \tilde{r}_{2 n} \\ \vdots & \ddots & \ldots & \vdots \\ \tilde{r}_{m 1} & \tilde{r}_{m 2} & \ldots & \tilde{r}_{m n}\end{array}\right]$

$$
\begin{aligned}
\tilde{r}_{i j} & =\left(\frac{a_{i j}}{c_{j}^{+}}, \frac{b_{i j}}{c_{j}^{+}}, \frac{c_{i j}}{c_{j}^{+}}\right) v e \\
c_{j}^{+} & =\max _{i}{ }^{c i j} \text { (fayda kriteri) }
\end{aligned}
$$

$$
\begin{aligned}
& \tilde{r}_{i j}=\left(\frac{a_{j}^{-}}{c_{i j}}, \frac{a_{j}^{-}}{b_{i j}}, \frac{a_{j}^{-}}{a_{i j}}\right) v e \\
& a_{j}^{-}=\min _{i} a i j \text { (maliyet kriteri) }
\end{aligned}
$$

Ağırlıklı normalize edilmiş bulanık karar matrisi şöyledir:

$\tilde{v}_{i j}=\left[\begin{array}{cccc}w_{1} \tilde{r}_{11} & w_{2} \tilde{r}_{12} & \ldots & w_{n} \tilde{r}_{1 n} \\ w_{1} \tilde{r}_{21} & w_{2} \tilde{r}_{22} & \ldots & w_{n} \tilde{r}_{2 n} \\ \cdot & \cdot & \cdot & \cdot \\ \cdot & \cdot & \cdot & \cdot \\ \cdot & \cdot & \cdot & \cdot \\ w_{1} \tilde{r}_{m 1} & w_{2} \tilde{r}_{m 2} & \ldots & w_{n} \tilde{r}_{m n}\end{array}\right]$

$i=1,2, \ldots, m$;

$j=1,2, \ldots, n$ iken $\tilde{v}_{i j}=\tilde{r}_{i j(.)} w_{j}$

Bulanık pozitif ve negatif ideal çözümler şöyledir:

$A^{+}=\left\{\tilde{v}_{1}^{+}, \tilde{v}_{2}^{+}, \ldots, \tilde{v}_{n}^{+}\right\}$iken $\tilde{v}_{j}^{+}=(1,1,1)$

$A^{-}=\left\{\tilde{v}_{1}^{-}, \tilde{v}_{2}^{-}, \ldots, \tilde{v}_{n}^{-}\right\}$iken $\tilde{v}_{j}^{-}=(0,0,0)$

Ayrım ölçümlerinin belirlenmesi aşağıdaki gibidir:

$d_{i}^{+}=\sum_{j=1}^{n} d v\left(\tilde{v}_{i j}, \tilde{v}_{j}^{+}\right), i=1,2, \ldots, m$

$d_{i}^{-}=\sum_{j=1}^{n} d v\left(\tilde{v}_{i j}, \tilde{v}_{j}^{-}\right), i=1,2, \ldots, m$

Eğer $\tilde{v}_{i j}=\left(\tilde{a}_{i j}, \tilde{b}_{i j}, \tilde{c}_{i j}\right) v e$ 
$\tilde{v}_{j}^{+}=(1,1,1)$ ve $\tilde{v}_{j}^{-}=(0,0,0):$

$d v\left(\tilde{v}_{i j}, \tilde{v}_{j}^{+}\right)=\sqrt{\frac{1}{3}\left[\left(\tilde{a}_{i j}-1\right)^{2}+\left(\tilde{b}_{i j}-1\right)^{2}+\left(\tilde{c}_{i j}-1\right)^{2}\right]}$,

$d v\left(\tilde{v}_{i j}, \tilde{v}_{j}^{-}\right)=\sqrt{\frac{1}{3}\left[\left(\tilde{a}_{i j}-0\right)^{2}+\left(\tilde{b}_{i j}-0\right)^{2}+\left(\tilde{c}_{i j}-0\right)^{2}\right]}$.

Yakınlık katsayısının belirlenmesi aşağıdaki gibidir:

$C C_{i}=\frac{d_{i}^{-}}{d_{i}^{-}+d_{i}^{+}}$

Çalışmada takip edilen modelin uygulama aşamaları Şekil 2'de gösterilmiştir.

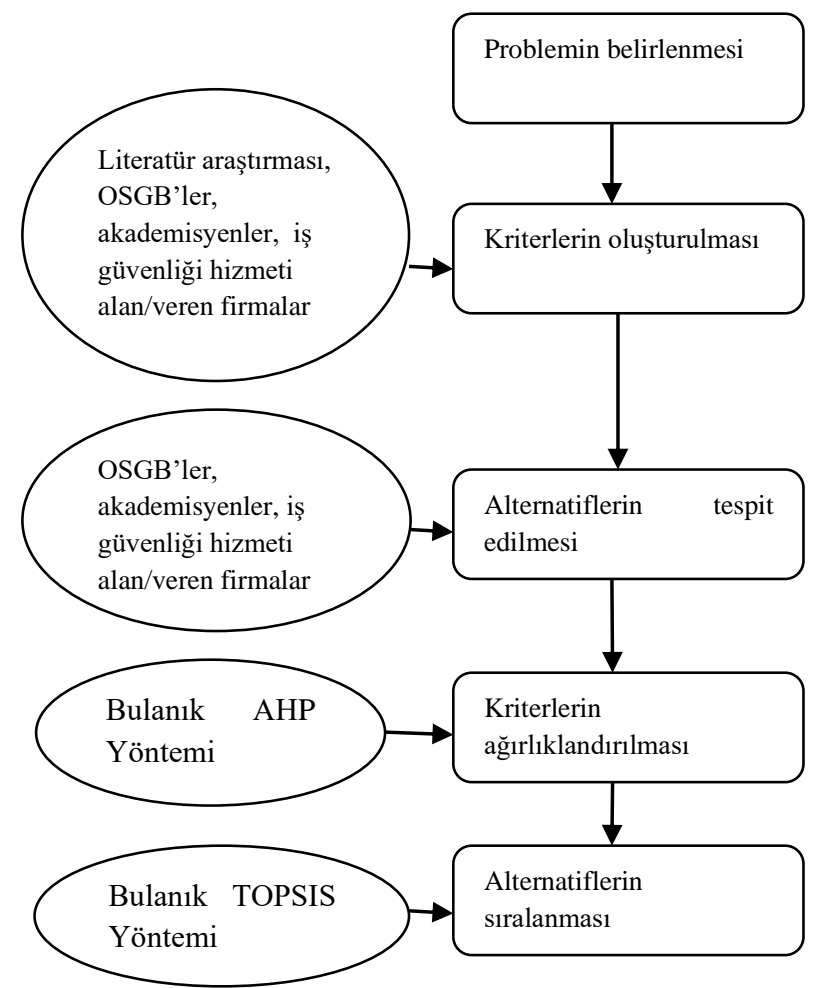

Şekil 2. Modelin uygulama aşamaları
İş güvenliği uzmanı seçimi için bulanık AHP- bulanık TOPSIS yöntemleri önerilmiştir. Problemin hiyerarşik yapısı Şekil 3'te gösterilmiştir. Beş aday beş kriter doğrultusunda değerlendirmeye tabi tutulmuştur. OSGB'de beş yıldan fazla süredir çalışmakta olan üç karar vericinin görüşleri anket yardımıyla alınmıştır. Karar vericilerin (uzmanların) görüşleri Tablo 4'te gösterilmiştir. Kriter ağırlıkları belirlenirken bulanık AHP yaklaşımı uygulanmıştır. "Materyal ve metot" bölümünde ifade edildiği gibi karar vericilerin görüşleri tek matriste birleştirilmiştir. Her bir kriterin ağırlığı ve birleştirilmiş ikili karşılaştırma matrisi Tablo 5'te sunulmuştur. Daha sonra kriterler önem ağırlıklarına göre sirasıyla "bilgisayar yeteneği" (0.243), "bireysel özellikler ve dış görünüm" (0.242), "tecrübe/iş deneyimi" $(0,2235)$, "yabancı dil bilgisi” $(0,1906)$, “eğitim düzeyi” $(0,0994)$ olarak hesaplanmıştır. En önemli kriterin bilgisayar yeteneği" en az önemli kriterin ise "eğitim düzeyi” olduğu görülmektedir.

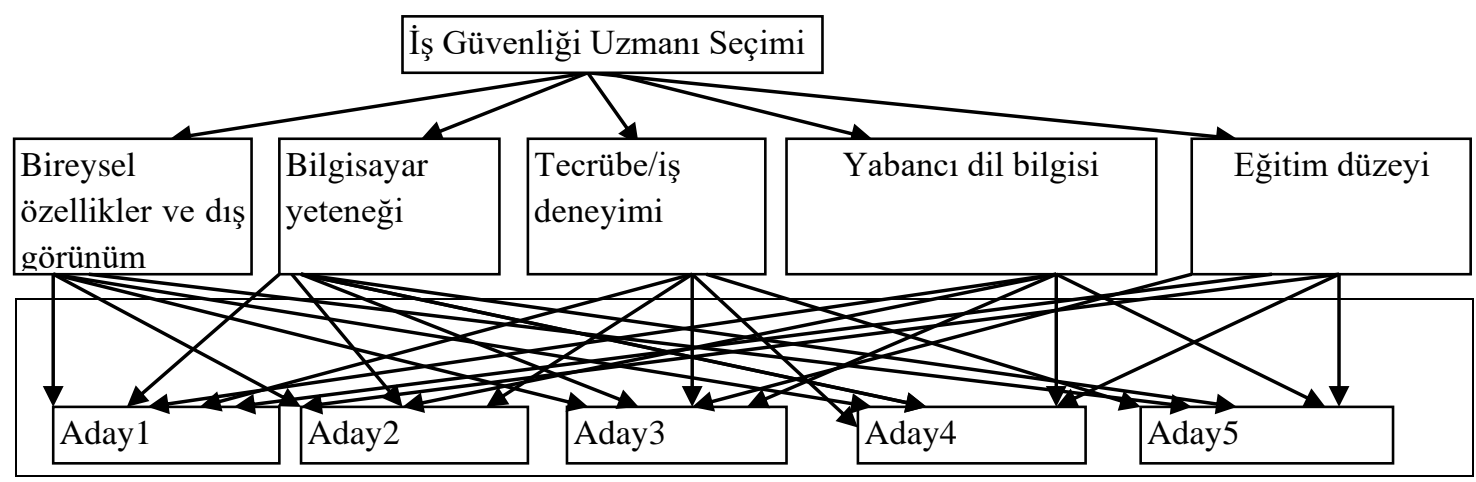

Şekil 3. Problemin hiyerarşik yapısı 
Tablo 4. Kriterler için karar vericilerin görüşleri

\begin{tabular}{|c|c|c|c|c|c|c|}
\hline & & $K_{1}$ & $\mathbf{K}_{2}$ & $\mathbf{K}_{3}$ & $\mathbf{K}_{4}$ & $\mathbf{K}_{\mathbf{5}}$ \\
\hline & $\mathbf{K}_{1}$ & $\mathrm{E}$ & $\overline{B G}$ & ÇG & $\overline{B G}$ & $\overline{C ̧ G}$ \\
\hline \multirow[t]{6}{*}{ U1 } & $\mathbf{K}_{2}$ & BG & E & ÇG & BG & MG \\
\hline & $\mathbf{K}_{\mathbf{3}}$ & 1/ÇG & 1/ÇG & $\mathrm{E}$ & BG & ÇG \\
\hline & $\mathbf{K}_{4}$ & BG & BG & BG & $\mathrm{E}$ & ÇG \\
\hline & $\mathbf{K}_{5}$ & 1/ÇG & $1 / \mathrm{MG}$ & 1/ÇG & 1/ÇG & E \\
\hline & & $K_{1}$ & $\mathbf{K}_{2}$ & $\mathbf{K}_{3}$ & $\mathbf{K}_{4}$ & $\mathbf{K}_{\mathbf{5}}$ \\
\hline & $\mathbf{K}_{1}$ & $\mathrm{E}$ & ÇG & MG & 1/BG & MG \\
\hline \multirow[t]{6}{*}{ U2 } & $\mathbf{K}_{2}$ & 1/ÇG & $\mathrm{E}$ & ÇG & KDG & KDG \\
\hline & $\mathbf{K}_{3}$ & $1 / \mathrm{MG}$ & 1/ÇG & E & ÇG & ÇG \\
\hline & $\mathbf{K}_{4}$ & BG & $1 / \mathrm{KDG}$ & 1/ÇG & E & KDG \\
\hline & $\mathbf{K}_{5}$ & $1 / \mathrm{MG}$ & $1 / \mathrm{KDG}$ & 1/ÇG & $1 / \mathrm{KDG}$ & $\mathrm{E}$ \\
\hline & & $\mathbf{K}_{1}$ & $\mathbf{K}_{2}$ & $\mathbf{K}_{3}$ & $\mathbf{K}_{4}$ & $K_{5}$ \\
\hline & $\overline{K_{1}}$ & $\mathrm{E}$ & $\mathrm{E}$ & $1 / \mathrm{BG}$ & $\mathrm{E}$ & $1 / \mathrm{BG}$ \\
\hline \multirow[t]{4}{*}{ U3 } & $\mathbf{K}_{2}$ & $\mathrm{E}$ & E & KDG & ÇG & KDG \\
\hline & $\mathbf{K}_{3}$ & BG & $1 / \mathrm{KDG}$ & E & ÇG & MG \\
\hline & $\mathbf{K}_{4}$ & $\mathrm{E}$ & 1/ÇG & $1 / C ̧ G$ & $\mathrm{E}$ & KDG \\
\hline & $\mathbf{K}_{5}$ & BG & $1 / \mathrm{KDG}$ & $1 / \mathrm{MG}$ & $1 / \mathrm{KDG}$ & $\mathrm{E}$ \\
\hline
\end{tabular}

Tablo 5. Her bir kriterin ağırlığı ve ikili karşılaştırma matrisi

\begin{tabular}{|c|c|c|c|c|c|c|c|c|c|c|c|c|c|c|c|c|}
\hline & \multicolumn{3}{|c|}{$\mathbf{K}_{1}$} & \multicolumn{2}{|r|}{$\mathbf{K}_{2}$} & \multicolumn{3}{|c|}{$\mathbf{K}_{\mathbf{3}}$} & \multicolumn{2}{|r|}{$\mathbf{K}_{4}$} & \multicolumn{3}{|c|}{$\mathbf{K}_{5}$} & \multicolumn{3}{|r|}{ Ağırlık } \\
\hline$K_{1}$ & 1,00 & 1,00 & 1,00 & 0,67 & 1,67 & 3,50 & 0,67 & 2,67 & 4,50 & 0,67 & 1,00 & 1,50 & 0,67 & 2,67 & 4,50 & $\mathbf{0 , 2 4 2 7}$ \\
\hline $\mathbf{K}_{2}$ & 0,29 & 0,78 & 1,50 & 1,00 & 1,00 & 1,00 & 1,50 & 2,67 & 3,50 & 0,67 & 2,00 & 3,50 & 1,50 & 2,67 & 4,50 & 0,2438 \\
\hline $\mathbf{K}_{3}$ & 0,22 & 0,53 & 1,50 & 0,29 & 0,39 & 0,67 & 1,00 & 1,00 & 1,00 & 0,67 & 2,33 & 3,50 & 2,50 & 3,33 & 4,50 & 0,2235 \\
\hline $\mathbf{K}_{4}$ & 0,67 & 1,00 & 1,50 & 0,29 & 0,61 & 1,50 & 0,29 & 0,56 & 1,50 & 1,00 & 1,00 & 1,00 & 1,50 & 2,33 & 3,50 & 0,1906 \\
\hline$K_{5}$ & 0,22 & 0,53 & 1,50 &, 22 & 0,42 & 67 & 42 & 0,31 & 0,40 & 0,2 & 0 & 06 & 10 & 1,00 & 1,00 & 00 \\
\hline
\end{tabular}

Kriter ağırlıkları AHP yöntemi ile normalize edilmiş bulanık karar matrisi belirlendikten sonra bulanık TOPSIS Tablo 7'de gösterilmiştir.

kullanılarak kriterler temelinde alternatifler (A) sıralanmıştır. Üç karar vericinin uzman görüşlerine ait dilsel ifadeler Tablo 6'da gösterilmiştir. Alternatifler için ağırlıklı Tablo 6. Alternatifler için karar vericilerin görüşleri 


\begin{tabular}{|c|c|c|c|c|c|c|}
\hline & & $\mathbf{K}_{1}$ & $\mathbf{K}_{2}$ & $\mathbf{K}_{\mathbf{3}}$ & $\mathbf{K}_{4}$ & $\mathbf{K}_{\mathbf{5}}$ \\
\hline & $\mathrm{A}_{1}$ & Çİ & $\dot{\mathrm{I}}$ & $\mathrm{O}$ & $\mathrm{Z}$ & $\dot{\mathrm{I}}$ \\
\hline \multirow[t]{6}{*}{ U1 } & $\mathrm{A}_{2}$ & $\dot{\mathrm{I}}$ & Çİ & ÇZ & $\mathrm{O}$ & $\mathrm{Z}$ \\
\hline & $\mathrm{A}_{3}$ & $\mathrm{O}$ & İ & Çİ & ÇZ & $\mathrm{O}$ \\
\hline & $\mathrm{A}_{4}$ & $\mathrm{Z}$ & İ & $\mathrm{O}$ & Çİ & İ \\
\hline & $\mathrm{A}_{5}$ & ÇZ & $\mathrm{O}$ & İ & $\mathrm{O}$ & İ \\
\hline & & $\mathbf{K}_{1}$ & $\mathbf{K}_{2}$ & $\mathbf{K}_{\mathbf{3}}$ & $\mathbf{K}_{4}$ & $\mathbf{K}_{5}$ \\
\hline & $\mathrm{A}_{1}$ & $\dot{\mathrm{I}}$ & Çİ & $\dot{\mathrm{I}}$ & ÇZ & $\mathrm{O}$ \\
\hline \multirow[t]{6}{*}{ U2 } & $\mathrm{A}_{2}$ & Çİ & İ & $\mathrm{Z}$ & $\mathrm{O}$ & $\mathrm{Z}$ \\
\hline & $\mathrm{A}_{3}$ & $\dot{\mathrm{I}}$ & $\mathrm{O}$ & $\mathrm{O}$ & Z & $\mathrm{O}$ \\
\hline & $\mathrm{A}_{4}$ & $\mathrm{O}$ & $\mathrm{Z}$ & Çİ & $\dot{I}$ & İ \\
\hline & $\mathrm{A}_{5}$ & $\mathrm{Z}$ & İ & ÇZ & $\mathrm{O}$ & Çİ \\
\hline & & $\mathbf{K}_{\mathbf{1}}$ & $\mathbf{K}_{\mathbf{2}}$ & $\mathbf{K}_{\mathbf{3}}$ & $\mathbf{K}_{4}$ & $\mathbf{K}_{5}$ \\
\hline & $\mathrm{A}_{1}$ & $\dot{\mathrm{I}}$ & $\mathrm{O}$ & $\mathrm{O}$ & ÇZ & Ç் \\
\hline \multirow[t]{4}{*}{ U3 } & $\mathrm{A}_{2}$ & $\dot{\mathrm{I}}$ & $\dot{I}$ & $\mathrm{Z}$ & $\dot{I}$ & $\mathrm{Z}$ \\
\hline & $\mathrm{A}_{3}$ & $\mathrm{O}$ & $\mathrm{O}$ & $\dot{\mathrm{I}}$ & ÇZ & $\mathrm{O}$ \\
\hline & $\mathrm{A}_{4}$ & $\mathrm{Z}$ & İ & $\mathrm{O}$ & Çİ & $\mathrm{O}$ \\
\hline & $\mathrm{A}_{5}$ & $\mathrm{Z}$ & $\mathrm{O}$ & Ç் & $\mathrm{O}$ & $\dot{\mathrm{I}}$ \\
\hline
\end{tabular}

Tablo 7. Alternatifler için ağırlıklı normalize edilmiş bulanık karar matrisi

\begin{tabular}{|c|c|c|c|c|c|c|c|c|c|c|c|c|c|c|c|}
\hline & \multicolumn{3}{|c|}{$K_{1}$} & \multicolumn{3}{|c|}{$\mathbf{K}_{2}$} & \multicolumn{3}{|c|}{$\mathbf{K}_{3}$} & \multicolumn{3}{|c|}{$\mathbf{K}_{4}$} & \multicolumn{3}{|c|}{$\mathbf{K}_{5}$} \\
\hline $\mathbf{A}_{1}$ & 0,1103 & 0,1692 & 0,2427 & 0,0665 & 0,1552 & 0,2438 & 0,0610 & 0,1151 & 0,1829 & 0,0173 & 0,0289 & 0,0866 & 0,0271 & 0,0632 & 0,0994 \\
\hline $\mathbf{A}_{2}$ & 0,1103 & 0,1692 & 0,2427 & 0,1108 & 0,1699 & 0,2438 & 0,0203 & 0,0474 & 0,1016 & 0,0520 & 0,0982 & 0,1559 & 0,0090 & 0,0271 & 0,0452 \\
\hline $\mathbf{A}_{3}$ & 0,0662 & 0,1250 & 0,1986 & 0,0665 & 0,1256 & 0,1995 & 0,0610 & 0,1422 & 0,2235 & 0,0173 & 0,0289 & 0,0866 & 0,0271 & 0,0452 & 0,0632 \\
\hline $\mathbf{A}_{4}$ & 0,0221 & 0,0809 & 0,1544 & 0,0222 & 0,1256 & 0,1995 & 0,0610 & 0,1287 & 0,2235 & 0,0866 & 0,1444 & 0,1906 & 0,0271 & 0,0572 & 0,0813 \\
\hline A5 & 0,0221 & 0,0515 & 0,1103 & 0,0665 & 0,1256 & 0,1995 & 0,0203 & 0,1151 & 0,2235 & 0,0520 & 0,0866 & 0,1213 & 0,0452 & 0,0693 & 0,0994 \\
\hline
\end{tabular}

Tablo 7'deki veriler bulanık TOPSIS yönteminde kullanılmış ve Tablo 8 'deki sonuçlar elde edilmiştir. Tablo 8'de görüldüğü gibi mesafe temelli ölçümlerde alternatif 1 (0.1199) en iyi personel olarak seçilmiştir. Mesafe temelli ölçümlerde tüm alternatiflerin siralamas $A_{1}>A_{4}>A_{2}>A_{3}>$ $A_{5}$ olarak bulunmuştur. En iyi alternatif 1 ve en kötü alternatif 5 olarak bulunmuştur.
Tablo 8. Mesafe temelli ayrım ölçüleri ve yakınlık katsayıs1

\begin{tabular}{llllc}
\hline & $\mathrm{d}^{+}$ & $\mathrm{d}^{-}$ & $\mathrm{CC}_{\mathrm{i}}$ & Siralama \\
\hline $\mathrm{A}_{1}$ & 4,4508 & 0,6066 & $0,1199 *$ & $1^{*}$ \\
\hline $\mathrm{A}_{2}$ & 4,4708 & 0,5726 & 0,1135 & 3 \\
\hline $\mathrm{A}_{3}$ & 4,5144 & 0,5403 & 0,1069 & 4 \\
\hline $\mathrm{A}_{4}$ & 4,4735 & 0,5975 & 0,1178 & 2 \\
\hline $\mathrm{A}_{5}$ & 4,5376 & 0,5243 & 0,1036 & 5 \\
\hline
\end{tabular}


Örnek olarak alternatif 1 için mesafe temelli ayrım ölçüleri ve yakınlık katsayısı hesaplanmıştır.

$$
\begin{aligned}
& \left(d_{1}^{+}\right)=\sqrt{\frac{1}{3}\left[(1-0,1103)^{2}+(1-0,1692)^{2}+(1-0,2427)^{2}\right]}+ \\
& \sqrt{\frac{1}{3}\left[(1-0,0665)^{2}+(1-0,1552)^{2}+(1-0,2438)^{2}\right]+} \\
& \sqrt{\frac{1}{3}\left[(1-0,061)^{2}+(1-0,1151)^{2}+(1-0,1829)^{2}\right]+} \\
& \sqrt{\frac{1}{3}\left[(1-0,0173)^{2}+(1-0,0289)^{2}+(1-0,0866)^{2}\right]+} \\
& \sqrt{\frac{1}{3}\left[(1-0,0271)^{2}+(1-0,0632)^{2}+(1-0,0994)^{2}\right]} \\
& =4,4508 \\
& \left(d_{1}^{-}\right)=\sqrt{\frac{1}{3}\left[(1-0,1103)^{2}+(1-0,1692)^{2}+(1-0,2427)^{2}\right]}+ \\
& \sqrt{\frac{1}{3}\left[(0-0,0665)^{2}+(0-0,1552)^{2}+(0-0,2438)^{2}\right]+} \\
& \sqrt{\frac{1}{3}\left[(0-0,061)^{2}+(0-0,1151)^{2}+(0-0,1829)^{2}\right]+} \\
& \sqrt{\frac{1}{3}\left[(0-0,1173)^{2}+(0-0,0289)^{2}+(0-0,0866)^{2}\right]+} \\
& \sqrt{\frac{1}{3}\left[(0-0,0271)^{2}+(0-0,0632)^{2}+(0-0,0994)^{2}\right]} \\
& =0,066 \\
& C C_{i}=\frac{d_{i}^{-}}{d_{i}^{-}+d_{i}^{+}} \quad \text { ise, } \\
& C C_{i}=\frac{0,066}{0,066+4,4508}=0,1199 \text {. }
\end{aligned}
$$

\section{Sonuç ve Tartışma}

İşletmelerin devamlılığg ve prestiji açısından iş güvenliği çalışmaları önem arz etmektedir. $\mathrm{Bu}$ çalışmaların etkin bir şekilde yürütülmesi için alternatifler arasından en iyi iş güvenliği uzmanının seçimi ve istihdamı önemlidir. Bu çalışmada bir iş güvenliği uzmanı için personel seçimi problemi ele alınarak bulanık AHP ve bulanık TOPSIS bütünleşik yaklaşımını kullanan çok kriterli karar verme modeli geliştirilmiştir. Literatürde personel seçiminde birçok sektörde birbirinden farklı alanlarda personel seçimi çalışmaları yapılmıştır. $\mathrm{Bu}$ çalışmada ise literatürdeki yapılmış olan çalışmalardan farklı olarak iş güvenliği uzmanı seçiminde uygulanmıştır. Bulanık TOPSIS yaklaşımında mesafe temelli çözümler sunulmuştur. İş güvenliği uzmanı olarak işe alımlarda en önemli kriter "bilgisayar yeteneğii" (0.243), en az öneme sahip kriter ise "eğitim düzeyi" (0.099) bulunmuştur. $\mathrm{Bu}$ sonuca göre işe alımlarda bilgisayar yeteneğine sahip personel adaylarının avantajlı olduğu belirlenmiştir. $\mathrm{Bu}$ durum iş sağlığı ve güvenliği ile ilgili yapılan çalışmaların birçoğunun zorunlu yönetmelikler doğrultusunda yapılıyor olması, benzer çalışmaların başka yerlerde rahatlikla uyarlanabilmesi ve kullanılabilmesi kaynaklıdır. Yeterli düzeyde bilgisayar kullanabilme becerisine sahip çalışanların işverenlerce yeterli olacağı düşünülmektedir. Bilgisayarda Office programlarını etkin olarak kullanabilen birisi rahatlıkla risk analizi ve acil durum eylem planı dokümanlarını hazırlayabilir algısı mevcuttur. Bilgisayar kullanma becerisi kadar önemli olan bir diğer kriter $(0,2427)$ ise "bireysel özellikler ve diş görünüm" olarak hesaplanmıştır. Bu durum iş sağlığ 1 ve güvenliği faaliyetlerin işletmenin tüm kademelerinde kabul görmesi için ihtiyaç duyulan bir özelliktir. Eğitimleri planlama, uygulama, çalışanlarla karşılıklı iletişimin ve disiplinli çalışma ortamının oluşturulması bu kriterin altında düşünülmektedir. İş güvenliği uzmanı olmak için, önlisans/lisans iş sağlığ güvenliği mezunu olmak ya da mühendislik/fen fakültesi mezunu olmak gerekmektedir. İş sağlığg ve güvenliği ile ilgili yapılacak çalışmalarda bu durum düşünüldüğünden dolayı işverenlerce sertifikayı almaya hak kazanan herkesin bu işi yapabilmek için yeterli eğitim düzeyine sahip olduğu algısı bulunmaktadır. Ayrıca işverenlerce daha az maaşın verilmek 
istenmesi de bu durumu etkilemektedir. Bundan dolayı eğitim düzeyi kriterinin en az öneme sahip çıktığı düşünülmektedir. Ancak özellikle maden gibi çok tehlikeli işlerde o meslek sahibi iş güvenliği uzmanlarının tercih edildiği bilinmektedir. Çalışmadan elde edilen sonuçlara göre en uygun adayın alternatif 1 , en kötü adayın ise alternatif 5 olduğu görülmüştür. Önerilen yöntem belirsiz ortamda karar vermede karar vericilere yardımcı olmakla birlikte, birçok farklı alanda uygulanabilme imkanına sahiptir. Farklı bütünleşik çok kriterli karar verme yöntemleri gelecek çalışmalarda kullanılabilir.

\section{Kaynaklar}

Akça, N., Sönmez, S., Gür, Ş., Y1lmaz, A.,Eren, T. 2018. "Kamu Hastanelerinde Analitik A $\breve{g}$ Süreci Yöntemi ile Finans Yöneticisi Seçimi”, Optimum Ekonomi ve Yönetim Bilimleri Dergisi, 5(2):133146.

Aksakal, E., Dağdeviren, M. 2010. “ANP ve DEMATEL Yöntemleri ile Personel Seçimi Problemine Bütünleşik Yaklaşım”, Gazi Üniversitesi Mühendislik Mimarlık Fakültesi Dergisi, 25(4), 905-913.

Arvey, R. D., Campion, J. E. 1982. "The employment interview: A summary and review of recent research", Personel Psychology, 35(1), 281-322.

Bedir, N., Eren, T. 2015. “AHPPROMETHEE Yöntemleri Entegrasyonu ile Personel Seçim Problemi: Perakende Sektöründe Bir Uygulama", Social Sciences Research Journal, 4(4): 46-58.

Bohanec, M., Urh, B., Rajkovic, V. 1992. "Evaluating options by combined qualitative and quantitative methods", Acta Psychologica, 80(1-3), 67-89.

Chang, D. Y. 1996. "Applications of the ex tent analysis method on fuzzy AHP",
European Journal of Operational Research, 95(3), 649-655.

Chen, C. T., Hwang, Y. C., Hung, W. Z. 2009. "Applying multiple linguistic PROMETHEE method for personnel evaluation and selection", International Conference on Industrial Engineering and Engineering Management, IEEM, Hong Kong.

Chen, L. Y. and Wang, T. C. 2009. 'Optimizing partners' choice in IS/IT Outsourcing Projects: The Strategic Decision of Fuzzy VIKOR", International Journal of Production Economics, 120(1), 233-242.

Dağdeviren, M. 2007. "Bulanık Analitik Hiyerarşi Prosesi İle Personel Seçimi ve Bir Uygulama", Gazi Üniversitesi Mühendislik Mimarlık Fakültesi Dergisi 22(4), 791-799.

Dereli, T., Durmuşoğlu A., Seçkiner S. U., Avlanmaz, N. 2010. "A Fuzzy Approach for Personnel Selection Process",Turkish Journal of Fuzzy Systems, 1(2):126-140.

Dodangeh, J., Sorooshian, S., Afshari, A. R. 2014. " Linguistic Extension for Group Multicriteria Project Manager election", Journal of Applied Mathematics, v. 2014.

Dursun, E. M. ve Karsak, E. E. 2010. “A Fuzzy MCDM Approach for Personel Selection", Expert Systems with Applications, 37:4324-4330.

Efe, B. 2016. An integrated fuzzy multi criteria group decision making approach for ERP system selection. Applied Soft Computing, 38, 106-117.

Efe, B., Boran, F. E., Kurt, M. 2015. "Sezgisel Bulanık Topsis Yöntemi Kullanılarak Ergonomik Ürün Konsept Seçimi”, SDÜ Mühendislik Bilimleri ve Tasartm Dergisi, 3(3), 433-440.

Efe, B., Efe, Ö. F. 2018. "Intuitionistic fuzzy number based group decision making approach for personnel selection", Uluda ̆ University Journal of The Faculty of Engineering, 23(3), 11-26. 
Efe, B., Kurt, M. 2018. "A systematic approach for an application of personel selection in assembly line balancing problem", International Transactions in Operational Research, 25(3), 1001-1025.

Erden, C., Karayel, H., Demir, H. İ., Kökçam , A. H. 2019. "Selection of the Best LNG Natural Gas Supplier with Multi-Criteria Decision-Making Techniques: Turkey Example in Current Conditions", Journal of Emerging Economies and Policy, 4(1), 1330.

Ervural, B. Ç., Ervural, B., Kahraman, C. 2016. "Fuzzy Sets in the Evaluation of Socio-Ecological Systems: An IntervalValued Intuitionistic Fuzzy Multi- criteria Approach", Fuzzy Logic in Its 50th Year, 341, 309-326.

Gardiner, A. R., Armstrong-Wright, D. 2000. "Employee selection and anti-discrimination law: Implications for multi-criteria group decision support", Journal of Multi-Criteria Decision Analysis, 9(1), 99-109.

Hwang, C. L., Yoon, K. (1981). Multiple attribute decision making methods and Applications, Springer-Verlag Berlin Heidelberg, Lecture Notes in Economics and Mathematical Systems, 186, New York.

Junior F. R. L., Osiro L., Carpinetti L. C. R. 2014. "A comparison between Fuzzy AHP and Fuzzy TOPSIS methods to supplier selection", Applied Soft Computing, 21:194209.

Kabak, M. 2013. “A fuzzy DEMATEL-ANP based multi criteria decision making approach for personnel selection", Journal of Multiple-Valued Logic and Soft Computing, 20(5), 571-593.

Kaynak, T. (1998). İnsan Kaynakları Yönetimi, I. Ü. Işsletme Fakültesi Yayınları, İstanbul.

Kelemenis, A. Askounis, D. 2010. "A new TOPSIS-based multi-criteria approach to personnel selection", Expert Systems with Applications, 37(7), 4999-5008.

Lee, A. H. 2009. "A fuzzy supplier selection selection model with the consideration of benefits opportunities, costs and risks", Expert Systems with Applications, 36(2), 2879-2893.

Özgörmüş, E., Mutlu, Ö., Güner, H. 2005. "Bulanık AHP ile Personel Seçimi", $V$. Ulusal Üretim Araştırmaları Sempozyumu, İstanbul Ticaret Üniversitesi, İstanbul.

Sabuncuoğlu, Z. (2000). İnsan Kaynakları Yönetimi, Ezgi Yayınevi, Bursa.

Shaw, K., Shankar, R., Yadav, S. S., Thakur, L. S. 2012. "Supplier selection using fuzzy AHP and fuzzy multi-objective linear programming for developing low carbon supply chain", Expert Systems with Applications, 39, 8182-8192.

Timmermans, D., Vlek, C. 1992. "Multiattribute decision support and complexity: An evaluation and process analysis of aided versus unaided decision making", Acta Psychologica, 80(1), 49-65.

Yerlikaya, M. A., Arıkan, F. 2017. “AHP kritik bütünleşik yaklaşımı ile akreditasyon temelli tedarikçi Seçimi”, TINI-SOS, 5(5), 627-635.

Zhang, S. F., Liu, S. Y. 2011. "A GRA-based intuitionistic fuzzy multi-criteria group decision making method for personnel selection", Expert Systems with Applica., 38(9), 11401-11405.

Zolfani, S. H., Rezaeiniya, N., Aghdaie, M. H., Zavadskas, E.M. 2012. "Quality control manager selection based on AHP-COPRASG methods: A case in Iran", Economic Research, 25(1), 72-86. 